\title{
A Descriptive Analysis of Psychosocial Factors Associated With Non- fatal Adolescent Suicide Attempts
}

\author{
Kumar KK ${ }^{1}$, Sattar FA ${ }^{2}$, Veluswamy $P^{3}$, Bondade $S^{4}$ \\ ${ }^{1}$ Dr. Kiran Kumar K., MD (Psychiatry), Assistant professor, ${ }^{2}$ Dr. Fiaz Ahmed Sattar, MD (Psychiatry), Professor and \\ Head, ${ }^{3}$ Dr. Pradeep Veluswamy., MBBS, Junior Resident, Department of Psychiatry, Vydehi Institute of Medical \\ Sciences and Research Center, Bangalore, Department of Psychiatry, ${ }^{4}$ Dr. Swapna Bondade, MD (Psychiatry), Associate \\ professor, The Oxford Medical college, hospital and research center, Bangalore, India.
}

Address for Correspondence: Dr. Kiran Kumar K., Assistant Professor, Room No. 112, Department of Psychiatry, Vydehi Institute of Medical Sciences and Research Center, EPIP Area, Whitefield, Bangalore. E: drkiran.psychiatry@gmail.com

\begin{abstract}
Introduction: Adolescence is the tender, vulnerable transition period with umpteen challenges and individual vulnerability. Various Psychosocial factors play a determinantal role in the genesis of adolescent suicide attempts and the present descriptive study tries to analyze some common psychosocial factors in cases of non-fatal adolescent suicide attempters. Method: Fifty subjects were recruited in the study. Detailed assessment of psychiatric morbidity and attempted suicide was done by clinical interview and validated by M.I.N.I.- KID, Beck Suicide Intent Scale and Adolescent Suicide Assessment Protocol-20. Psychosocial factors associated with the attempt were documented with the semi-structured proforma and descriptive statistical analysis was done with the help of SPSS version 15 . Results: Majority of the suicide attempters were in the age group of 18-19 years and females (54\%) outnumbered males (46\%). Most of the subjects were single $(88 \%)$, Hindu $(86 \%)$ by religion, belonged to middle socioeconomic class $(82 \%)$ and were from the urban background $(80 \%)$. Two third of them belonged to nuclear family and half of them were students. In our evaluation of various psychosocial factors, $76 \%$ of subjects were found to have psychosocial stressor, in that $10 \%$ had two or more stressors. Family related factors were the most common $(60 \%)$ followed by college related factors $(26 \%)$ in which most common was love failure (12\%). Conclusion: A sizeable proportion of subjects had various psychosocial factors associated with non-fatal adolescent suicide attempts and emphasis on these factors can help in prevention and hence monitoring of at-risk adolescents.
\end{abstract}

Key words: Adolescents, Psychosocial factors, Suicide attempts.

\section{Introduction}

Suicide is a major public health concern and WHO estimates that nearly 900,000 people worldwide die from suicide every year [1]. Today, 1.2 billion adolescents stand at the crossroads between childhood and the adult world and 243 million of them live in India [2]. Adolescents constitute 21 per cent of the population of India and this is the generation which will shape India's future [3]. Premature deaths among adolescents are a tragedy; where the death is selfinflicted, it is often bewildering.

Manuscript received: $26^{\text {th }}$ Jan 2016

Reviewed: $07^{\text {st }} \mathrm{Feb} 2016$

Author Corrected: $17^{\text {st }} \mathrm{Feb} 2016$

Accepted for Publication: $28^{\text {th }}$ Feb 2016
The number of adolescent suicides over the past several decades has tripled or quadrupled [4]. Suicidal behaviors amongst adolescents is a matter of great concern and according to the American Academy of Paediatrics, committee on adolescence, suicide is the third leading cause of death for adolescents 15 to 19 years old [5]. Global Adolescent Suicide Rate is 14.5 per 100,000. For every adolescent suicide, there are between 50 and 200 suicide attempts. In both early and late adolescents, suicide attempters are more than completers and this has huge consequences [6]. Adolescence is a period characterized by rapid physical, biological and hormonal changes resulting into 
psychosocial, behavioral and sexual maturation. These bio-psychosocial factors play an important role in determining the adolescent behavior towards suicide. Adolescent suicidal behavior has been characterized as a multidimensional construct constituting a complex relationship between psychosocial and environmental components. Factors like lack of social support, academic pressure, poverty, interpersonal conflict, previous suicidal behavior, cultural transition, and acculturation as well as the use of inadequate coping strategies have been identified [7]. Adolescence is widely considered to be a period of increased stress resulting from the multilayered personal, cognitive and social development that accompanies this life stage [8]. Since attempted suicide in adolescence is a complex phenomenon where in psychosocial factors play a crucial role, the current study was carried out with an aim of studying the various psychosocial factors associated with non-fatal adolescent suicide attempts.

\section{Materials and Methods}

This is a descriptive type of observational study conducted from January 2011 to September 2012 on non-fatal adolescent suicide attempters in the age group of 10-19 years; attending Psychiatry department at Vydehi Institute of Medical Sciences and Research Centre, Whitefield, Bangalore. 'Any act of self-damage inflicted with self-destructive intentions, however vague and ambiguous' was taken as a suicide attempt for the purpose of the study [9]. Fifty cases of adolescent suicide attempters referred from various departments were included after obtaining a written informed consent. Patients whose injuries were considered to be accidental in origin with no suggestion of self harm intention, and those succumbed to their injuries, were excluded from the study. The patients were interviewed once their general condition improved. Next of Kin (NOK) of each patient were interviewed with the patients' consent for any additional information. Confidentiality of the information obtained was ensured to the patient. Patients who did not consent for the study and who were critically ill to co-operate for assessment were excluded from the study. The study protocol was approved by the Institutional Ethics Committee.

\section{Tools used:}

\section{Informed Consent.}

2. Semi-structured proforma for recording sociodemographic variables, details of suicide attempt, medical and psychiatric history.
3. Kuppuswamy's socioeconomic status scale [10].

4. MINI International Neuropsychiatric Interview for Children \& Adolescents [M.I.N.I.- KID] [11].

5. Beck Suicide Intent Scale [12]: It is a 20-item interviewer administered assessment of the intensity of an attempter's wish to die at the time of the index attempt. The scale is completed using retrospective data obtained from the patient. The total scores obtained are categorized into the following subgroups; 1 . Low intent (0-6), 2. Moderate intent (7-12), 3. High intent (13-20) and 4 . Very high intent $(21+)$

6. Adolescent Suicide Assessment Protocol-20 (ASAP) [13]: The ASAP-20 was developed from a careful review of the adolescent suicide risk literature to identify both static and dynamic factors associated with both adolescent attempted and completed suicides. ASAP-20 presents the 20 items most discriminating of ratings of low, medium and high risk of suicide by mental health professionals of adolescents who are presenting for initial evaluation. ASAP-20 is organized into four domains: Historical, Clinical, Contextual and Protective.

7. Semi-structured proforma for assessing psychosocial factors.

Written informed consent was taken following an explanation about nature and purpose of the study in a language best understood by the patient and NOK. The socio-demographic variables of the patient were recorded in the semi-structured proforma. A detailed history, physical examination and mental status examination were recorded in a proforma designed for the study.

The assessment of suicide was done by clinical interview and supported by Beck Suicide Intent Scale and Adolescent Suicide Assessment Protocol-20. The Psychiatric morbidity was assessed independently by a faculty and validated by M.I.N.I.- KID and coded as per International Classification of Disorders (ICD-10). Psychosocial factors contributing to the attempt was documented with the help of a semi-structured proforma for assessing psychosocial factors.

Statistics: Data was analyzed using SPSS package version 15.0. The data was expressed using mean, median and standard deviation for continuous variables and frequency and percentages for categorical variables. 


\section{Results}

The current study had a sample of 50 cases. Majority of the suicide attempters were in the age group of 18-19 years $(74 \%)$ and females $(54 \%)$ marginally out numbered males $(46 \%)$. Majority of the subjects were single (88\%), Hindu $(86 \%)$ by religion, belonged to middle socioeconomic class $(82 \%)$ and were from the urban background (80\%). Two third of them belonged to nuclear family and half of our subjects were students. Half of our subjects had attempted suicide by poison consumption (46\%), followed by drug overdose $(42 \%)$ while method of hanging was opted by $12 \%$. Maximum people (88\%) in our sample had attempted suicide once. In terms of lethality of the attempt, $50 \%$ of our subjects were found to have high lethality. Sixty per cent had attempted suicide in an impulse, whereas $40 \%$ had done planning prior to attempt.

Table 1: Details of Suicide Attempt $(\mathbf{N}=50)$

\begin{tabular}{|c|c|c|}
\hline Variable & $\mathbf{n}$ & $\%$ \\
\hline \multicolumn{3}{|l|}{ Method of Attempt } \\
\hline Hanging & 6 & 12 \\
\hline Poison Consumption & 23 & 46 \\
\hline Drug Overdose & 21 & 42 \\
\hline \multicolumn{3}{|l|}{ Nature of Attempt } \\
\hline Planned & 20 & 40 \\
\hline Impulsive & 30 & 60 \\
\hline \multicolumn{3}{|c|}{ Communication with Family Members } \\
\hline Yes & 6 & 12 \\
\hline No & 44 & 88 \\
\hline \multicolumn{3}{|c|}{ Present attempt under the influence of Alcohol } \\
\hline Yes & 0 & 0 \\
\hline No & 50 & 100 \\
\hline \multicolumn{3}{|l|}{ Number of Attempts } \\
\hline 1 & 44 & 88 \\
\hline $2-5$ & 6 & 12 \\
\hline$>5$ & 0 & 0 \\
\hline \multicolumn{3}{|l|}{ Lethality } \\
\hline High & 25 & 50 \\
\hline Low & 25 & 50 \\
\hline$>5$ & 0 & 0 \\
\hline
\end{tabular}


Maximum of our subjects $(88 \%)$ had not communicated anytime to family members before the attempt. Adolescent Suicide Assessment Protocol showed 18\% had high risk appraisal, 4\% had medium risk appraisal, $88 \%$ had low risk appraisal. Forty per cent of adolescent attempters had moderate intent, 32\% had high intent, 26\% had low intent and $2 \%$ had very high intent on Beck Suicide Intent Scale. (Table 1 and Table 2)

Table 2: Assessment of Suicide Risk Appraisal and Intent (N=50)

\begin{tabular}{|c|c|c|}
\hline Variable & $\mathbf{n}$ & $\%$ \\
\hline \multicolumn{3}{|c|}{ Adolescent Suicide Assessment Protocol } \\
\hline Low $(0-15)$ & 44 & 88 \\
\hline Medium (16-19) & 2 & 4 \\
\hline High (20+) & 4 & 8 \\
\hline \multicolumn{3}{|c|}{ Beck Suicide Intent Scale } \\
\hline Low (0-6) & 13 & 26 \\
\hline Moderate (7-12) & 20 & 40 \\
\hline High (13-20) & 16 & 32 \\
\hline Very High $(21+)$ & 1 & 2 \\
\hline
\end{tabular}

In our study we found $86 \%$ of subjects had psychiatric diagnosis as assessed by M.I.N.I.- KID. Among which, $40 \%$ of the subjects had the diagnosis of Adjustment Disorder (40\%), followed by Depressive Episode (MDD) amounting for $22 \%$ and Dysthymia in $8 \%$. Psychosis NOS was seen in 6\%. Conduct Disorder was found in 4\%. Generalized Anxiety Disorder, Manic episode and Opioid Dependence Syndrome were amounting for $2 \%$ each. None of our subjects had dual diagnosis. (Table 3)

Table 3: Psychiatric Morbidity (N=50)

\begin{tabular}{|l|l|l|}
\hline Psychiatric Diagnosis & $\mathbf{n}$ & $\mathbf{\%}$ \\
\hline Adjustment Disorder-Prolonged Depressive Reaction & 13 & $26 \%$ \\
\hline Adjustment Disorder -Brief Depressive Reaction & 7 & $14 \%$ \\
\hline Depressive Episode (MDD) & 11 & $22 \%$ \\
\hline Dysthymia & 4 & $8 \%$ \\
\hline Psychosis NOS & 3 & $6 \%$ \\
\hline Conduct Disorder & 2 & $4 \%$ \\
\hline Generalized Anxiety Disorder & 1 & $2 \%$ \\
\hline Manic Episode & 1 & $2 \%$ \\
\hline Opioid Dependence Syndrome & 1 & $2 \%$ \\
\hline Hyperkinetic Disorder & 0 & $0 \%$ \\
\hline No Diagnosis & 7 & $14 \%$ \\
\hline
\end{tabular}

In our evaluation of various psychosocial factors, $76 \%$ of subjects were found to have psychosocial stressor, in that $10 \%$ had two or more stressors. When we evaluated family related factors we found most common was conflict with mother amounting for $20 \%$, next was family conflict with other members $(16 \%)$ and conflict with father (14\%) and few subjects reported conflicts with siblings $(6 \%)$ and in-laws $(4 \%)$. College related factors were found in $26 \%$ of subjects in which most common was love failure (12\%). Twelve per cent people had marital problems. Twelve per cent of subjects reported conflicts with peers. Unfulfilled commitments at work as a stressor were reported by one subject. Six per cent of subjects had financial problems. One subject reported bereavement as the principal stressor. 
Very few of our subjects were diagnosed with and had past history of psychiatric illness (2\%) and medical illness (2\%) prior to attempting suicide, but none of our subjects were taking any treatment for mental or medical disorder prior to the attempt. Six per cent had positive family history of Deliberate Self Harm whereas $4 \%$ had history of substance dependence in the family. In our study 38 (76\%) subjects had only one psychosocial stressor associated with the suicidal attempt, and $10(20 \%)$ subjects had 2 or more psychosocial factors associated with the suicidal attempt. (Table 4, Table 5 and Table 6)

Table 4: Psychosocial Factors $(\mathbf{N}=50)$

\begin{tabular}{|c|c|c|c|c|c|c|c|c|c|c|c|c|c|c|}
\hline \multicolumn{3}{|c|}{ Family Related } & \multicolumn{3}{|c|}{$\begin{array}{l}\text { School/College } \\
\text { Related }\end{array}$} & \multicolumn{3}{|c|}{ Marital Related } & \multicolumn{3}{|c|}{ Peer Related } & \multicolumn{3}{|c|}{ Work Related } \\
\hline $\begin{array}{l}\text { Variabl } \\
\text { e }\end{array}$ & $\mathbf{n}$ & $\%$ & Variable & $\mathbf{n}$ & $\%$ & Variable & $\mathbf{n}$ & $\%$ & Variable & $\mathbf{n}$ & $\%$ & Variable & $\mathbf{n}$ & $\%$ \\
\hline $\begin{array}{l}\text { No } \\
\text { problem } \\
\text { s } \\
\text { related } \\
\text { to } \\
\text { family }\end{array}$ & $\begin{array}{l}2 \\
0\end{array}$ & $\begin{array}{l}40.0 \\
\%\end{array}$ & $\begin{array}{l}\text { Change of } \\
\text { school }\end{array}$ & 3 & $6.0 \%$ & Marriage & 6 & $\begin{array}{l}12 \\
\%\end{array}$ & $\begin{array}{l}\text { Conflicts } \\
\text { with peers }\end{array}$ & 6 & $\begin{array}{l}12 \\
\%\end{array}$ & Loss of job & 0 & $\begin{array}{l}0 \\
\%\end{array}$ \\
\hline $\begin{array}{l}\text { Family } \\
\text { conflict }\end{array}$ & 8 & $\begin{array}{l}16.0 \\
\%\end{array}$ & $\begin{array}{l}\text { Exam } \\
\text { failure }\end{array}$ & 3 & $6.0 \%$ & Divorce & 0 & $0 \%$ & $\begin{array}{l}\text { Romantic } \\
\text { relationshi } \\
\text { p with } \\
\text { peers }\end{array}$ & 0 & $0 \%$ & $\begin{array}{l}\text { Trouble at } \\
\text { work with } \\
\text { superiors }\end{array}$ & 0 & $\begin{array}{l}0 \\
\%\end{array}$ \\
\hline $\begin{array}{l}\text { Conflict } \\
\text { with } \\
\text { mother }\end{array}$ & $\begin{array}{l}1 \\
0\end{array}$ & $\begin{array}{l}20.0 \\
\%\end{array}$ & $\begin{array}{l}\text { Poor } \\
\text { scholastic } \\
\text { performan } \\
\text { ce }\end{array}$ & 1 & $2.0 \%$ & $\begin{array}{l}\text { Broken } \\
\text { engagement }\end{array}$ & 0 & $0 \%$ & $\begin{array}{l}\text { Suicide in } \\
\text { peers }\end{array}$ & 0 & $0 \%$ & $\begin{array}{l}\text { Trouble at } \\
\text { work with } \\
\text { subordinat } \\
\text { es }\end{array}$ & 0 & $\begin{array}{l}0 \\
\%\end{array}$ \\
\hline $\begin{array}{l}\text { Conflict } \\
\text { with } \\
\text { father }\end{array}$ & 7 & $\begin{array}{l}14.0 \\
\%\end{array}$ & $\begin{array}{l}\text { Love } \\
\text { failure }\end{array}$ & 6 & $\begin{array}{l}12.0 \\
\%\end{array}$ & $\begin{array}{l}\text { Marital } \\
\text { reconciliati } \\
\text { on }\end{array}$ & 0 & $0 \%$ & $\begin{array}{l}\text { Marriage } \\
\text { of adoring } \\
\text { personalit } \\
\text { y }\end{array}$ & 0 & $0 \%$ & $\begin{array}{l}\text { Trouble at } \\
\text { work with } \\
\text { colleagues }\end{array}$ & 0 & $\begin{array}{l}0 \\
\%\end{array}$ \\
\hline
\end{tabular}

Table 5: Cumulative Effects of Psychosocial Factors ( $\mathrm{N}=50)$

\begin{tabular}{|l|l|l|}
\hline Number of Psychosocial Factors & $\mathbf{n}$ & $\mathbf{\%}$ \\
\hline 1 Factor & 38 & $76 \%$ \\
\hline 2 Factors & 8 & $16 \%$ \\
\hline 3 Factors & 0 & $0 \%$ \\
\hline 4 Factors & 2 & $4 \%$ \\
\hline 5 Factors & 0 & $0 \%$ \\
\hline 6 Factors & 0 & $0 \%$ \\
\hline Nil Factors & 2 & $4 \%$ \\
\hline
\end{tabular}

\section{Discussion}

Most of the adolescents (74\%) who had attempted suicide were in the age group of 18 and 19 years. The mean age was 17.88 which corroborates with the study of Kumar et al where mean age of the sample was 17.58 [14]. Age group of 18-19 years is more demanding as there is transition from adolescent to the adulthood, decision regarding the career and more demands from the relationship can be the reasons for increased suicide attempt rate in this age group. In the current study, it was found that among the adolescent suicide attempters, $46 \%$ were males and $54 \%$ were females. Females had outnumbered the males. This is in corroboration of 
many studies carried out in suicide and these studies have reported females to show suicidal thoughts and suicide attempts significantly more often than the males $[14,15]$. In our study, $78 \%$ of the adolescent suicide attempters were unmarried while $22 \%$ were married. Since the legal age of marriage in our country is 18 for females and 21 for males, all the married subjects in the study population were female patients $(22 \%)$. It is estimated there are worldwide more than 51 million adolescent girls aged 15-19 who are married and bearing the burden of domestic responsibility and the risks associated with early sexual activity, including pregnancy. In South Asia in 2005, 48\% (nearly 10 million) of young women were married before the age of 18 [16]. Despite a shift towards later marriages in many parts of the world, in the countries of South Asia a majority of girls still marry before age 18 (65\% in Bangladesh, 57\% in Nepal, 54\% in Afghanistan, and almost 50\% in India) [17]. This phenomenon of early marriage of adolescent girls is multidimensional in nature with various consequences and projects new dimensions as risk factors for the suicide attempt. This might also explain the increased risk of suicide attempts in female adolescent population. Seventy-six per cent of the sample population of adolescent suicide attempters belonged to urban areas. This can be related to our hospital's geographical location being urban. However, the effects of modernization and urbanization have led to sweeping changes in the socioeconomic, sociophilosophical and cultural arenas of people's lives, which have greatly added to the stress in life, leading to substantially higher rates of suicide [18]. In the current study $80 \%$ of the adolescent suicide attempters belonged to nuclear families and surprisingly the proportion of adolescent suicide attempters from a three to four membered family in our study was $64 \%$. Singh $\mathrm{H}$ et al. found that stress was more among adolescents belonging to nuclear families [19]. The current day nuclear family is highly stressed with each family member struggling for his/her own existence. There is little time left to address the needs of the vulnerable adolescent population and adding to it, lack of a sibling in the family makes it even worse. Kumar et.al in his study of adolescent suicides has also reported an over representation of subjects from nuclear families $(56.8 \%)$ [14]. In the present study, $86 \%$ of adolescent suicide attempters belonged to Hindu religion. This finding can be explained on the grounds that majority of population in our vicinity belong to Hindu religion. In the current study, $58 \%$ of adolescent suicide attempters were students. This may be because of the urban population sample and the age group falls in the age of schooling and college years. Majority of adolescent suicide attempters were from middle socioeconomic status $(82 \%)$ in the current study. As our hospital is located in an Information Technology (IT) corridor, there is an over representation of Middle SES. Mathur and Freeman (2002) had argued that higher SES could increase suicide risk among adolescents as parental time is directed toward economic activities rather than childcare [20]. However, Donald Langille B et.al had reported that lower socio-economic status is associated with adolescent risk behaviors [21].

In our study, it was found that about $46 \%$ of adolescents attempted suicide by poison consumption and $42 \%$ of adolescents attempted suicide by drug overdose. Twelve per cent of adolescents attempted suicide by hanging. (Table 1) Variations in the degree of availability have an important influence on the methods of suicide chosen by adolescents. Aaron et al., (2004) in their study of Rural population of 108,000 in the age group of 10-19 yrs found that commonest method of suicide attempt was Hanging $(44 \%)>$ Poisoning $(40 \%)$ $>$ self-immolation (9\%) [22]. According to the NCRB 2013 report on Accidental Deaths and Suicides in India, the most common method of attempting suicide in children up to the age of 14 years was hanging ( $\mathrm{N}=806)$, followed by poisoning $(\mathrm{N}=496)$ and drowning (404) [23]. Deliberate self-poisoning has become an increasingly common response to emotional distress in young adults. Agrochemical pesticides have been reported as the most common cause of acute poisonings in the region [24]. We have found that the poison use for the attempt were those which were easily available in the house in the form of rat poison and repellents. Self-poisoning is the most common choice for attempted suicide in the Indian subcontinent [14]. Ponnudurai et al in one of their major studies in adolescents reported that $31.4 \%$ had used organophosphorus compounds, $16.28 \%$ - sleeping tablet, $15.12 \%$ - copper sulphate, $8.4 \%$ - burning and $8.14 \%$ oleander seeds [25]. Latha et al observed a similar trend and pointed out that violent methods such as drowning, hanging, jumping from a height and strangulation are rare [26]. In the west also the similar trends are seen, Shaffer in his research observed that between $80 \%$ to $90 \%$ of adolescents who were referred to the hospital after attempted suicide had taken overdose [27]. Sixty per cent of adolescent suicide attempts were impulsive and $40 \%$ were planned in our study. (Table 1) In young individual's impulsiveness and short term triggers such as relational conflicts may often set off suicidal events when they are 
superimposed on long-term underlying reasons that account for the vulnerability for suicidal behavior in stressful situations. Many young suicide attempters report that they spent only minutes between the decision and the actual attempt indicating a high degree of impulsiveness [28]. Only $6 \%$ of the adolescent suicide attempters had communicated their suicidal ideas to their family members prior to the attempt (Table 1), indicating high intentionality and impulsivity. Eightyeight per cent of adolescent suicide attempters were first time attempters and $12 \%$ had attempted previously. (Table 1) Previous suicidal attempt is an important risk factor for the index attempt, and this has been emphasized by various authors [14,29]. Lethality was high in $50 \%$ of the cases as the lethal doses of drugs and poison were used. (Table 1) Suicide attempters who make attempts of high medical lethality (e.g., hanging, shooting, or jumping) are at extremely high risk for completed suicide. However, an attempt of low lethality does not necessarily indicate low suicidal intent, especially in younger children whose cognitive immaturity makes it difficult to formulate and execute a suicidal plan. In an impulsive individual for whom a lethal agent such as a firearm or paracetamol is available, an attempt with relatively low intent may result in a medically serious and even fatal attempt [30]. In our study $40 \%$ of adolescent suicide attempters had moderate intent, $32 \%$ had high intent, $26 \%$ had low intent and $2 \%$ had very high intent on Beck Suicide Intent Scale. (Table 2) Studies have shown that there is no significant correlation between intent to die and the lethality of the attempt particularly in adolescent population [31]. The risk assessment was done by Adolescent Suicide Assessment Protocol-20 (ASAP-20) [32]. In our study it is found that $8 \%$ had high risk and $4 \%$ had medium risk for future suicidal behavior and $88 \%$ had low risk. (Table 2)

The following psychosocial risk factors studied in adolescent suicide attempters will be discussed.

Family Related: Sixty per cent of the cases had family related factors, $20 \%$ had conflict with mother, $14 \%$ with father, $6 \%$ with siblings, $4 \%$ with in-laws, $16 \%$ of the cases had other family conflicts which were not specified. (Table 4) According to the Hawton et al, precipitating events which have led to a suicide attempt are most often the interpersonal problems between the adolescent and his parents and peers [33]. Maladaptive parenting and childhood maltreatment may be associated with a risk for severe interpersonal difficulties during adolescence. These interpersonal difficulties may play a pivotal role in the development of suicidal behavior [34]. In an Indian study done by Kumar et al, $63.5 \%$ of adolescents who had attempted suicide reported of interpersonal problems as the main precipitating factor for the attempt [14]. There is a consistent literature linking family discord with youth suicide and suicide attempts $[35,36]$. So it is clear that when adolescents have problems in their close relationships with family members, they may lose important sources of social support which may in turn increase the risk for suicidal behavior.

School/College Related: Twenty-six per cent of the cases had school/college related factors, $6 \%$ had change of school, $6 \%$ had exam failure, $2 \%$ had poor scholastic performance, and $12 \%$ had love failure as the cause for attempting suicide. (Table 4) Wilburn et al reported that students who have consistently exhibited a pattern of academic failure may simply engage in risk-taking behaviors that predispose them to suicidality [37]. Brent et al reported that the risk of attempted suicide increases among school dropouts or after a period of absence from school [38]. Poor or an overachieved academic performance can serve as a precursor to stress, subsequent depression, and suicidality in adolescents because academically successful students experience greater amounts of stress than do their less successful peers because more successful students feel more pressure to maintain their level of performance. This pressure may cause them to increase the lethality of their suicidal intent [37].

Marital Related: In our study 11 were married and 6 were having marital related stress, which accounts for about $55 \%$ in the married group and all of them were female subjects. (Table 4) Joseph Raj et al reported $67.5 \%$ of the suicide attempters to be unmarried. Among the reported causes of suicide attempt, married females attempted suicide because of adjustment problems with husband and mother-in-law, forced marriage, and financial restraints [39]. Arcel et al studied the suicide attempts among Greek and Danish women and their relationships with their husbands and reported dependence on emotional and financial aspects, and housing as the decisive reasons for the women to stay in unsatisfying marriage [40]. Badrinarayana noted that the most common causes for suicidal attempt were disruption of relationship with key figure, high degree of disharmony with spouse, quarrel with girlfriend, and rejection. Ill treatment or lack of care by their husbands or mother-in-law, disappointment in love was also reported [41]. 
Peer Related: Twelve per cent of the cases had peer related problems as a psychosocial factor associated with suicide attempts. (Table 4) A sense of burdensomeness resulting from feeling that one is a burden on close others, low connectedness with peers and absence of peer support, problems with peers, has been associated with both adolescent deaths by suicide and suicide attempts [42]. Several studies have found an association between attempted suicide and having a friend who has made a suicide attempt, although this could be accounted for assortative friendships rather than the exposure [43]. Lewinshon has found that a recent suicide attempt by a friend was a significant predictor of a future suicide attempt even after controlling for depression and psychosocial risk factor [44].

Work/Occupation Related: In our study, it was found that about $2 \%$ of adolescent suicide attempters had work/occupation related problems as a psychosocial factor associated with suicide attempts. (Table 4) As most of our study sample belonged to student category, we have not found work/occupation related problems.

Financial Related: Six per cent of the cases had financial related problems as a psychosocial factor associated with suicide attempts. (Table 5) In a casecontrol study by Srivastava et al, a significant association was found between recent stressful life events (at least one event in last 6 months) like financial problems in $17.5 \%$ cases most of the problems included were losses, loan and unemployment, and other problems [45]. Joseph Raj et al reported that causative factors for attempting suicide in their study, females had more of adjustment problems and males had financial problems as the reasons for attempting suicide [39].

Bereavement: Two per cent of the cases had bereavement as a psychosocial factor associated with suicide attempts. (Table 5) Several studies found that loss of a parent or divorce or living apart from one or both biological parents is a significant risk factor for attempted suicide among adolescents [46]. Lewinshon et al found an association between loss of a parent prior to age of 12 and multiple suicide attempts [44]. Prigerson et al reported that subjects with syndromal levels of traumatic grief were approximately five times more likely to report suicidal ideation than were subjects with non syndromal levels of traumatic grief [47].
Health Related: In our study group none of the subjects reported health related issue as a psychosocial stressor. There was one case who had past history of medical illness, but it has not acted as a stressor in that patient. There are studies where there is association between chronic illness and suicidal behavior [48,49]. As none of the subjects had chronic illness causing functional impairment, this could not have acted as stressor in our study group. May be further including more number of subjects and checking for suicidal ideation and suicidal behavior in adolescents suffering from chronic illness would help to get the health related stressor in future studies.

Legal Related: None of the subjects in our study group had any law related issue as a psychosocial factor for the suicidal attempt. There were two cases of Conduct Disorder, but they did not consider the law related factor as a stressor. Most of the studies are done in the west on juvenile delinquents and there is paucity of literature in Indian context [50,51]. May be the population selected was from general adolescent population, we were not able to find law related stressor in our study group.

Sexual Related: In our study, none of the subjects reported any significant sexual related factors as a risk factor for the index suicidal attempt. It was found that girls, who report high distress about sexual abuse, have a threefold increased risk of suicidal thoughts and plans, compared to non-abused girls. Boys who report current high distress about sexual abuse have 10-fold increased risk for suicidal plans and threats, and 15-fold increased risk for suicide attempts, compared to non-abused boys [52]. Gay and bisexual adolescents have been reported to exhibit high rates of depression and have been reported to have rates of suicidal ideation and attempts 3 times higher than other adolescents [53].

Cumulative Effect of Psychosocial Factors: In our study $38(76 \%)$ subjects had only one psychosocial stressor associated with the suicidal attempt, and 10 (20 $\%)$ subjects had 2 or more psychosocial factors associated with the suicidal attempt. (Table 6) There were 6 male subjects and 4 female subjects in this group of 10 who had multiple psychosocial factors. Only one female was married whose marriage had taken place against her will. Six of them were students four belonged to the lower socioeconomic status. Six of our subject's attempts were impulsive. In these cases, 8 of them had family related psychosocial factor (males had an argument with father and females with the mother) 
and 2 had peer related psychosocial factor (love failure) as a precipitating factor for their impulsive suicidal attempt. The other psychosocial factor acting in these individuals was school or college related and peers related. The intentionality was high in 7 cases and lethality was high in 2 cases out of the 10 cases. All the cases had a psychiatric diagnosis. Five carried the diagnosis of Adjustment disorder and 2 had the diagnosis of Major Depressive Disorder and Conduct Disorder was present in 2 subjects and one subject was in Mania.

\section{Conclusion}

Suicide among adolescents is a serious and major issue. The increasing evidence of suicidal menace is creating a greater challenge for psychiatrists, social workers, public health personnel, sociologists and psychologists to identify the underlying factors. Understanding the psychosocial factors which promote suicidal tendencies and improvement in the mental health of the community is the urgent need of the hour.

Limitations: The current study is an observational cross sectional hospital based study with a small sample size and hence the results cannot be generalized.

\section{Funding: Nil,}

Conflict of interest: None.

Permission of IRB: Yes

\section{References}

1. WHO. The global burden of disease: 2004 update. Geneva: World Health Organization, 2008.

2. Adolescence- An Age of Opportunity. Available from: http://unicef.in/PressReleases/87/AdolescenceAn-Age-of. [Last accessed on 2015 September 6].

3. Census of India 2011. Available from: http://www.imaginmor.com/census-of-india-

2011.html. [Last accessed on 2015 September 6].

4. Sadock BJ, Sadock VA. Kaplan \& Sadock's Synopsis of Psychiatry, 10th ed. USA: Lippincott H. Williams and Wilkins, 2009, 1264pp.

5. Shain BN; American Academy of Pediatrics Committee on Adolescence. Suicide and suicide attempts in adolescents. Pediatrics. 2007 Sep;120(3):669-76.
6. Anthony Lake. The State of The World's Children 2011: Adolescence an Age of opportunity. New York: UNICEF February 2011. 138p.

7. Du Plessis ED. Psychosocial Factors As Predictors Of Suicidal Ideation Amongst Adolescents In The Free State Province: A Cross-Cultural Study. (Psychology thesis). University of the Free state; February 2012.

8. Sigelman CK., Rider, EA. Life-span human development. 5th ed. Belmont, California: Wadsworth; 2010.

9. Kar N. Profile of risk factors associated with suicide attempts: A study from Orissa, India. Indian J Psychiatry. 2010 Jan;52(1):48-56. doi: 10.4103/00195545.58895 .

10. Mishra D, Singh HP. Kuppuswamy's socioeconomic status scale--a revision. Indian J Pediatr. 2003 Mar;70(3):273-4.

11. Sheehan DV, Lecrubier Y, Sheehan KH, Amorim P, Janavs J, Weiller $\mathrm{E}$ et al. The Mini-International Neuropsychiatric Interview (M.I.N.I.): the development and validation of a structured diagnostic psychiatric interview for DSM-IV and ICD-10. J Clin Psychiatry. 1998;59 Suppl 20:22-33;quiz 34-57.

12. Beck AT, Kovacs M, Weissman A. Assessment of suicidal intention: the Scale for Suicide Ideation. J Consult Clin Psychol. 1979 Apr;47(2):343-52.

13. Fremouw WJ, Strunj JM, Tymer EA. Adolescent suicide assessment protocol-20. Available from: http://www.wvsuicidecouncil.org. [Last accessed on 2015 September 6].

14. Kumar CT, Chandrasekaran R. A study of psychosocial and clinical factors associated with adolescent suicide attempts. Indian J Psychiatry. 2000 Jul;42(3):237-42.

15. Wunderlich U, Bronisch T, Wittchen HU, Carter R. Gender differences in adolescents and young adults with suicidal behaviour. Acta Psychiatr Scand. 2001 Nov;104(5):332-9.

16. Early Marriage: A Harmful Traditional Practice: A Statistical Exploration. UNICEF, 2005. Available from http://www.unicef.org/publications/files/Early_Marriag e_12.lo.pdf. [Last accessed on 2015 September 6]. 
17. The State of the World's children. UNICEF, 2007. Available from http://www.unicef.org/publications/files/The_State_of_t he_Worlds_Children_2007_e.pdf. [Last accessed on 2015 September 6].

18. Gehlot PS, Nathawat SS. Suicide and family constellation in India. Am J Psychother. 1983 Apr;37(2):273-8.

19. Singh H, Sofat R, Gill PJ, Soni RK, Kaur L. Adolescent girls' anxieties -- role of stressful life events. Indian J Matern Child Health. 1990 Oct-Dec;1(4):1423.

20. Mathur VK, Freeman DG. A theoretical model of adolescent suicide and some evidence from US data. Health Econ. 2002 Dec;11(8):695-708.

21. Langille DB, Curtis L, Hughes J, Murphy GT. Association of socio-economic factors with health risk behaviours among high school students in rural Nova Scotia. Can J Public Health. 2003 Nov-Dec;94(6):4427.

22. Aaron R, Joseph A, Abraham S, Muliyil J, George K, Prasad J, Minz S, Abraham VJ, Bose A. Suicides in young people in rural southern India. Lancet. 2004 Apr 3;363(9415):1117-8.

23. National Crimes Records Bureau. Accidental Deaths and Suicides in India 2013. New Delhi: Ministry of Home Affairs, Government of India; 2014.

24. Bumbrah GS, Krishan K, Kanchan T, Sharma M, Sodhi GS. Phosphide poisoning: a review of literature. Forensic Sci Int. 2012 Jan 10;214(1-3):1-6. doi: 10.1016/j.forsciint.2011.06.018. Epub 2011 Jul 16.

25. Ponnudurai R, Jeyakar J, Saraswathy M. Attempted suicides in Madras. Indian J Psychiatry. 1986 Jan;28(1):59-62.

26. Saddichha S, Prasad MN, Saxena MK. Attempted suicides in India: a comprehensive look. Arch Suicide Res. 2010;14(1):56-65. doi: 10.1080/13811110903479060.

27. Shaffer D. Suicide in childhood and early adolescence. J Child Psychol Psychiatry. 1974 Oct;15(4):275-91.

28. Hepp U, Stulz N, Unger-Köppel J, Ajdacic-Gross $\mathrm{V}$. Methods of suicide used by children and adolescents.
Eur Child Adolesc Psychiatry. 2012 Feb;21(2):67-73. doi: 10.1007/s00787-011-0232-y. Epub 2011 Dec 1.

29. Miranda R, Scott M, Hicks R, Wilcox HC, Harris Munfakh JL, Shaffer DJ. Suicide attempt characteristics, diagnoses, and future attempts: comparing multiple attempters to single attempters and ideators. Am Acad Child Adolesc Psychiatry 2008 Jan; 47(1):32-40.

30. Bridge JA, Goldstein TR, Brent DA. Adolescent suicide and suicidal behavior. J Child Psychol Psychiatry. 2006 Mar-Apr;47(3-4):372-94.

31. Levy SR, Jurkovic GL, Spirito A. A multisystems analysis of adolescent suicide attempters. J Abnorm Child Psychol. 1995 Apr;23(2):221-34.

32. William JF, Julia MS, Elizabeth AT, Robert M. Adolescent Suicide Assessment Protocol-20. Available from: http://preventsuicidewv.org/wpcontent/uploads/2014/03/ASAP-20.pdf. [Last accessed on 2015 September 6].

33. Hawton K, O'Grady J, Osborn M, Cole D. Adolescents who take overdoses: their characteristics, problems and contacts with helping agencies. $\mathrm{Br} \mathrm{J}$ Psychiatry. 1982 Feb;140:118-23.

34. Johnson JG, Cohen P, Gould MS, Kasen S, Brown J, Brook JS. Childhood Adversities, Interpersonal Difficulties, and Risk for Suicide Attempts during Late Adolescence and Early Adulthood. Arch Gen Psychiatry 2002 Aug;59(8):741-9.

35. Asarnow JR, Carlson GA, Guthrie D. Coping strategies, self-perceptions, hopelessness, and perceived family environments in depressed and suicidal children. J Consult Clin Psychol. 1987 Jun;55(3):361-6.

36. Brent DA, Kolko DJ, Allan MJ, Brown RV. Suicidality in affectively disordered adolescent inpatients. J Am Acad Child Adolesc Psychiatry. 1990 Jul;29(4):586-93.

37. Wilburn VR, Smith DE. Stress, self-esteem, and suicidal ideation in late adolescents. Adolescence. 2005 Spring;40(157):33-45.

38. Brent DA, Moritz G, Bridge J, Perper J, Canobbio R. The impact of adolescent suicide on siblings and parents: a longitudinal follow-up. Suicide Life Threat Behav. 1996 Fall;26(3):253-9. 
39. Raj M, Kumaraiah V, Bhide AV. Social and clinical factors related to deliberate self-harm. NIMHANS J 2000;18(1\&2):3-18.

40. Arcel LT, Mantonakis J, Petersson B, Jemos J, Kaliteraki E. Suicide attempts among Greek and Danish women and the quality of their relationships with husbands or boyfriends. Acta Psychiatr Scand. 1992 Mar;85(3):189-95.

41. Badrinarayana A. Suicidal attempt in Gulbarga. Indian J Psychiatry 1977;19(4):69-70.

42. Katherine A, Timmons KA, Edward A, Selby EA, Peter M, Lewinsohn PM, Joiner TE. Parental Displacement and Adolescent Suicidality: Exploring the Role of Failed Belonging. Journal of Clinical Child \& Adolescent Psychology 2011;40(6):807-17.

43. Grossman DC, Milligan BC, Deyo RA. Risk factors for suicide attempts among Navajo adolescents. Am J Public Health. 1991 Jul;81(7):870-4.

44. Lewinsohn PM, Rohde P, Seeley JR. Psychosocial risk factors for future adolescent suicide attempts. J Consult Clin Psychol. 1994 Apr;62(2):297-305.

45. Srivastava MK, Sahoo RN, Ghotekar LH, Dutta S, Danabalan M, Dutta TK, Das AK. Risk factors associated with attempted suicide : a case control study. Indian J Psychiatry. 2004 Jan;46(1):33-8.

46. Agerbo E, Nordentoft M, Mortensen PB. Familial, psychiatric, and socioeconomic risk factors for suicide in young people: nested case-control study. BMJ. 2002 Jul 13;325(7355):74.
47. Prigerson HG, Bridge J, Maciejewski PK, Beery LC, Rosenheck RA, Jacobs SC, Bierhals AJ, Kupfer DJ, Brent DA. Influence of traumatic grief on suicidal ideation among young adults. Am J Psychiatry. 1999 Dec;156(12):1994-5.

48. Lewinsohn PM, Rohde P, Seeley JR. Adolescent suicidal ideation and attempts: Prevalence, risk factors, and clinical implications. Clinical Psychology Science and Practice 1996;3:25-36.

49. Brent DA. Overrepresentation of epileptics in a consecutive series of suicide attempters seen at a children's hospital, 1978-1983. J Am Acad Child Psychiatry. 1986 Mar;25(2):242-6.

50. Roberts AR, Bender K. Juvenile offender suicide: prevalence, risk factors, assessment, and crisis intervention protocols. Int J Emerg Ment Health. 2006 Fall;8(4):255-65.

51. DeHart DD, Smith HP, Kaminski RJ. Institutional responses to self-injurious behavior among inmates. J Correct Health Care. 2009 Apr;15(2):129-41; quiz 15960. doi: 10.1177/1078345809331444.

52. Martin G, Bergen HA, Richardson AS, Roeger L, Allison S. Sexual abuse and suicidality: gender differences in a large community sample of adolescents. Child Abuse Negl. 2004 May;28(5):491-503.

53. Shain BN; American Academy of Pediatrics Committee on Adolescence. Suicide and suicide attempts in adolescents. Pediatrics. 2007 Sep;120(3):669-76.

\section{How to cite this article?}

Kumar KK, Sattar FA, Veluswamy P, Bondade S A Descriptive Analysis of Psychosocial Factors Associated With Nonfatal Adolescent Suicide Attempts. Int J Med Res Rev 2016;4(2):205-215. doi: 10.17511/ijmrr.2016.i02.014. 